\title{
Ameloblastic fibro-odontoma in a 9-year-old boy
}

\author{
Tatsuo Okui ${ }^{1}$, Soichiro Ibaragi ${ }^{1}$, Tsuyoshi Shimo', Kiyofumi Takabatake², Mariko Fujita ${ }^{3}$, Nur Mohammad \\ Monsur Hassan ${ }^{4}$, Akira Sasaki ${ }^{1}$
}
'Department of Oral and Maxillofacial Surgery, Okayama University Graduate School of Medicine, Dentistry and Pharmaceutical Sciences, Okayama 700-8525, Japan.
${ }^{2}$ Department of Oral Pathology and Medicine, Okayama University Graduate School of Medicine, Dentistry and Pharmaceutical Sciences, Okayama 700-8525, Japan.
${ }^{3}$ Department of Oral and Maxillofacial Radiology, Okayama University Graduate School of Medicine, Dentistry and Pharmaceutical Sciences, Okayama 700-8525, Japan.
${ }^{4}$ School of Dentistry \& Health Sciences, Charles Sturt University, Orange, NSW 2975, Australia.

Correspondence to: Dr. Tatsuo Okui, Department of Oral and Maxillofacial Surgery, Okayama University Graduate School of Medicine, Dentistry and Pharmaceutical Sciences, Okayama 700-8525, Japan. E-mail: tatsuookui0921@gmail.com

How to cite this article: Okui T, Ibaragi S, Shimo T, Takabatake K, Fujita M, Hassan NMM, Sasaki A. Ameloblastic fibro-odontoma in a 9-year-old boy. Stomatological Dis Sci2018;2:7. http://dx.doi.org/10.20517/2573-0002.2017.23

Received: 28 Dec 2017 First Decision: 20 Apr 2018 Revised: 2 May 2018 Accepted: 25 May 2018 Published: 11 Jul 2018

Science Editor: Evangelia Piperi Copy Editor: Jun-Yao Li Production Editor: Cai-Hong Wang

\begin{abstract}
Ameloblastic fibro-odontoma (AFO) is a rare, benign mixed odontogenic tumor. A 9-year-old Japanese boy was referred to Okayama University Hospital in December 2013 for the evaluation of an unerupted tooth in his right lower mandible. A panoramic radiograph showed a well-defined multilocular radiolucent lesion extending from the right first molar to the ramus of the mandibular, containing radiopaque foci. The first molar was impacted by the lesion. The tumor was easily enucleated from the cortical bone, and the follicle of the first molar was removed. The first molar was preserved in the hope that it would erupt to the occlusal plane. At the 3-year follow-up there was no evidence of recurrence, and the right first molar had erupted to the occlusal plane.
\end{abstract}

Keywords: Ameloblastic fibro-odontoma, odontogenic tumor, cortical bone, odontogenic epithelium

\section{INTRODUCTION}

Ameloblastic fibro-odontoma (AFO) is a rare, benign mixed odontogenic tumor that account for $1 \%-3 \%$ of all odontogenic tumors ${ }^{[1,2]}$. Hooker ${ }^{[3]}$ reported the first case of AFO in 1967. In its 2005 classification of odontogenic tumors, the World Health Organization (WHO) classifies AFO as odontogenic epithelium with odontogenic ectomesenchyme, with or without hard tissue formation. AFOs usually occurs at an early life stage, and thus the patient's age is an important factor in the diagnosis of $\mathrm{AFO}^{[4,5]}$. The WHO classification

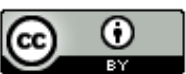

(C) The Author(s) 2018. Open Access This article is licensed under a Creative Commons Attribution 4.0 International License (https://creativecommons.org/licenses/by/4.0/), which permits unrestricted use, sharing, adaptation, distribution and reproduction in any medium or format, for any purpose, even commercially, as long as you give appropriate credit to the original author(s) and the source, provide a link to the Creative Commons license, and indicate if changes were made. 


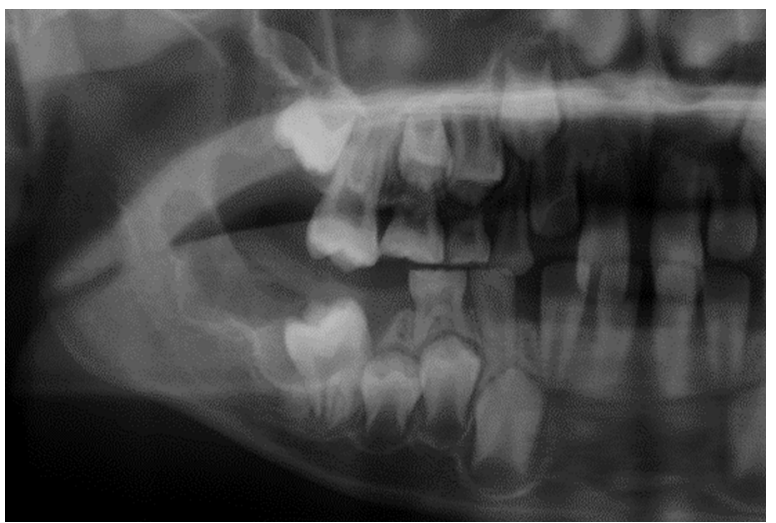

Figure 1. Panoramic radiograph. The right first molar was impacted by the well-defined radiolucent lesion

notes that there are no sex differences in AFO patients. However, Furst et al ${ }^{[6]}$ reported that AFOs are more common among males than female. The most characteristic clinical feature of AFOs is tooth eruption and swelling of the jaw. Radiographically, AFOs exhibit well-defined radiolucency with several levels of radiopacity depending on the extent of mineralization ${ }^{[7]}$. Here we report a new case of AFO in a young boy. We preserved his unerupted tooth without recurrence over a 2-year follow-up.

\section{CASE REPORT}

A 9-year-old Japanese boy was referred to Okayama University Hospital in December 2013 for the evaluation of an unerupted tooth in his right lower mandible as indicated by his family dentist. The results of the extraoral examination were normal. There was no gingival swelling or redness on his first molar lesion. An oral examination disclosed no expansion of the right mandible, and the gingiva mucosa in the lesion appeared normal. There was no history of local trauma or infection.

A panoramic radiograph showed a well-defined multilocular radiolucent lesion extending from the right first molar to the mandibular ramus, containing radiopaque foci. The first molar was impacted by the lesion [Figure 1]. Cone-beam computed tomography images showed a multilocular well-circumscribed radiolucent lesion containing several small scattered calcifications on the right side of the mandible. Axial and coronal views revealed no evident buccolingual expansion of the cortex, although thinning of the cortex on the lingual side was observed [Figure 2A and B]. Magnetic resonance imaging showed heterogenoushyperintensity on short tau inversion recovery (STIR) images [Figure $2 \mathrm{C}$ ] and intermediate intensity on T1-weighted images [Figure 2D]. The calcified body was detected as no signal on both the STIR and T1-weighted images.

Based on the clinical and radiographic findings, AFO and ameloblastic fibro-dentinoma were considered the likeliest diagnoses. Four weeks after the first medical examination, we treated the patient. Under local anesthesia, a mucoperiosteal flap was made by incision in the external oblique ridge to the deciduous canine. Thin cortical bone was removed, and the white elastic tumor was exposed. The tumor was easily enucleated from the cortical bone, and the follicle of the first molar was removed. The first molar was preserved in the hope that it would erupt to occlusal plane. The flap was sutured. At the 2-year follow-up there was no evidence of recurrence, and the right first molar had erupted to the occlusal plane [Figure $3 \mathrm{~A}$ and $\mathrm{B}$ ].

\section{Pathological evaluation}

Histopathological examination of the tumor specimen showed small islands and long strands of odontogenic epithelium in a cell-rich mesenchymal component. The structure of the epithelial component resembled the enamel organ in the peripheral cells are cuboidal or columnar. Stellate reticulum was observed in the central part of the epithelial tumor nest. The mesenchymal component was cell-rich and formed a dental papilla-like 

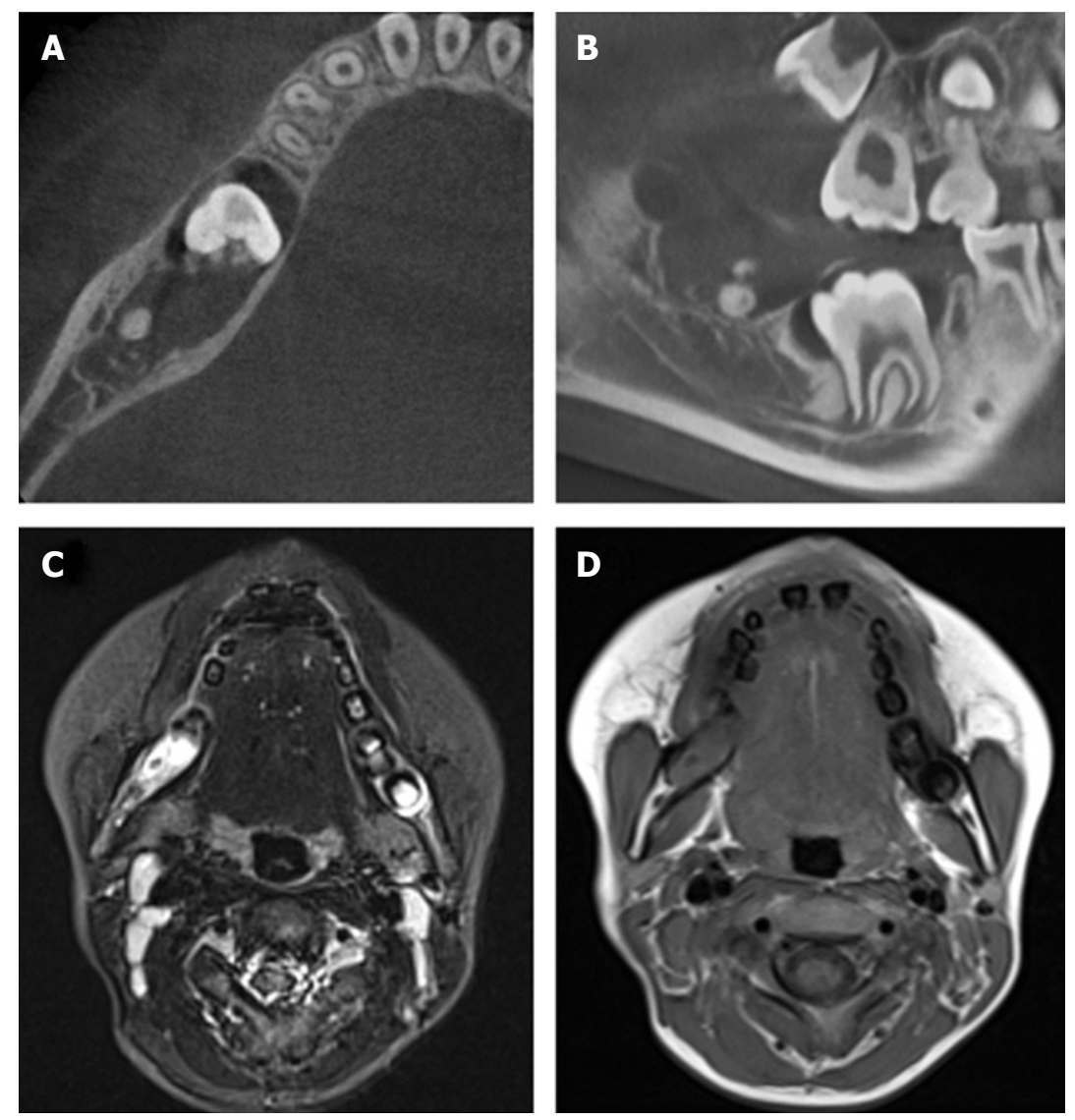

Figure 2. Horizontal (A) and sagittal cross section (B) cone-beam computed tomography showing multilocular well-circumscribed radiolucent lesion containing scattered calcifications. Magnetic resonance imaging on short tau inversion recovery image (C) and T1weighted image (D) showing calcification tissue
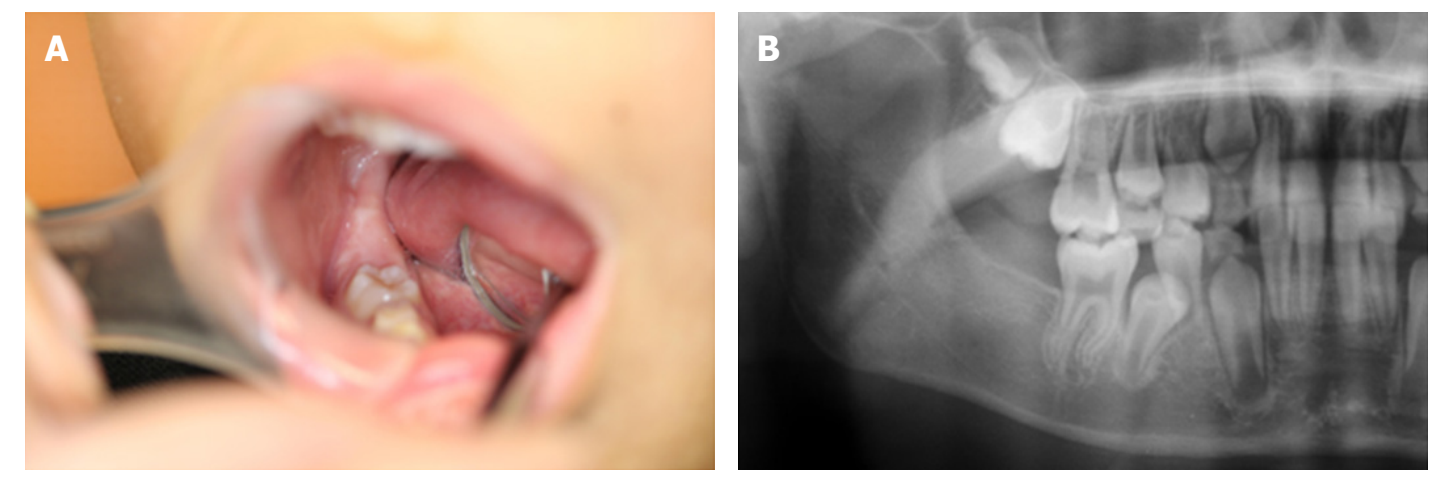

Figure 3. Follow up after 6 months from surgery intra oral photo $(A)$ and panoramic radiograph (B) showing erupted first molar

structure. Enamel matrix and dentin or osteodentin formation was seen within the ectomesenchymal tissue. These histological features confirmed the diagnosis of AFO [Figure 4].

\section{DISCUSSION}

AFO, a rare odontogenic tumor arising in oral lesions, was first reported in 1936 as rare case of ameloblastic fibroma ${ }^{[8]}$. Although a 1981 report stated that there was no difference in the prevalence of AFO between the sexes $^{[9]}$, more recent reports contend that AFOs are more likely to develop in males ${ }^{[6,7]}$. AFOs usually occur 


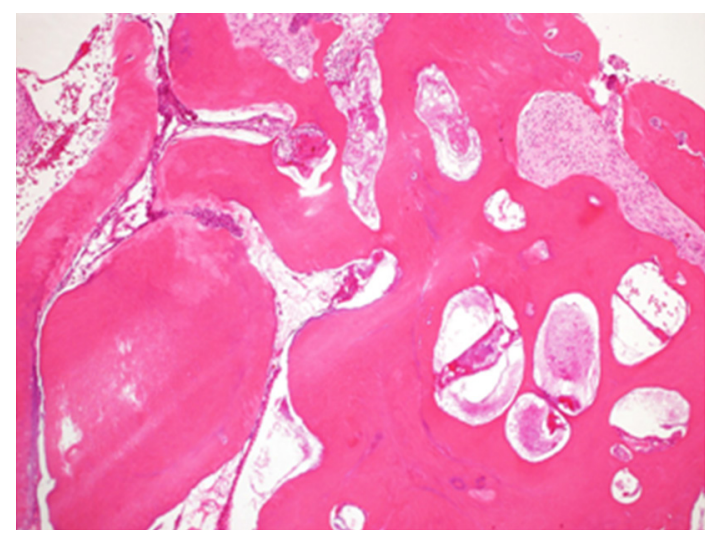

Figure 4. Hematoxylin-eosin stain ( $\times 20)$ : this lesion consists of soft and hard tissue components. The soft tissue component is identical to ameloblastic fibroma, the mesenchymal component was formed dental papilla like structure. The hard tissue component consists of dental hard structures or osteodenting, enamel organ. Enamel matrix formation was seen within the ectomesenchymal tissue

in the molar area $\mathrm{a}^{[3,10]}$. The sites of distribution tend to be located in the mandible $\mathrm{e}^{[7]}$. AFOs have generally been observed in young patients; almost all of the AFO patients reported to date were in their first two decades of life ${ }^{[4,5]}$.

There are several distinct opinions about the origin of AFOs. Some reports indicate that AFOs and complex odontomas develop from an ameloblast fibroma (AF). Other reports indicate that AF is the true neoplasm, and that AFO should be regarded as an immature complex odontoma. Yet other reports claim that AF and AFO are different pathological neoplasms. In the latest (4th) edition of the World Health Organization Classification of Head and Neck tumours, ameloblastic fibrodentinoma and ameloblastic fibro-odontoma are considered as part of the spectrum of histological changes seen in a developing odontoma ${ }^{[1,12]}$.

Buchner and Vered ${ }^{[11]}$ proposed that AF in younger patients may be either true neoplasms or odontomas in early stages of development. Clinical and radiologic characteristics can be some help of differential diagnosis.

In most cases of AFO, the surgical treatment is enucleation and extraction of the erupted tooth ${ }^{[13]}$. In the present case, we preserved the erupted first molar in light of the patient's age (9 years). Okura reported two AFO cases treated with the preservation of the unerupted tooth; the teeth erupted into occlusion after 2 years of observation ${ }^{[14]}$. However, Furst et al ${ }^{[6]}$ reported a case of recurrence after the preservation of the unerupted tooth. Friedrich et al ${ }^{[15]}$ indicated that there is a little potential for the recurrence of AFO. Howell and Burkes ${ }^{[5]}$ reported two cases of malignant transformation of AFO to ameloblastic fibrosarcoma. In that case, there was no evidence of recurrence and the tooth had erupted into the occlusal plane at the 2-year follow up.

In conclusion, we have reported a new case of AFO treated with preservation of the unerupted tooth. At the 2-year follow-up there was no evidence of recurrence, and the right first molar had erupted to the occlusal plane. However, longer follow-up examinations should be conducted to monitor the status of an erupted tooth after the enucleation of an AFO.

\section{DECLARATIONS}

\section{Authors' contributions}

Conception and design: Okui T, Ibaragi S, Shimo T, Sasaki A

Acquisition of data: Okui T, Ibaragi S, Takabatake K, Fujita M

Analysis and interpretation of data: Okui T, Hassan NMM 


\section{Availability of data and materials}

Raw data are available with the principal investigator Tatsuo Okui.

\section{Financial support and sponsorship}

None.

\section{Conflicts of interest}

All authors declare that there are no conflicts of interest.

\section{Ethical approval and consent to participate}

The ethical clearance for the study was obtained from the Faculty of Okayama University Hospital. Consent was obtained from patient and parents of patient.

\section{Consent for publication}

Not applicable.

\section{Copyright}

(c) The Author(s) 2018.

\section{REFERENCES}

1. Carvalho Silva GC, Jham BC, Silva EC, Rebello Horta MC, Pereira Godinho SH, Gomez RS. Ameloblastic fibro-odontoma. Oral Oncol Extra 2006;42:217-20.

2. Rad SAB, Mortazavi H, Eshghpour M, Salehinejad J, Shahakbari R. A large ameloblasticfibro-odontoma of the maxillary sinus. Iran J Otorhinolaryngol 2014;26:111-4.

3. Hooker SP. Ameloblasticodontoma: an analysis of twenty-six cases. Oral Surg Oral Med Oral Pathol Oral Radiol 1967;24:375-6.

4. Miller AS, López CF, Pullon PA, Elzay RP. Ameloblastic fibro-odontoma. Report of seven cases. Oral Surg Oral Med Oral Pathol 1976;41:354-65.

5. Howell RM, Burkes EJ. Malignant transformation of ameloblastic fibro-odontoma to ameloblasticfibrosarcoma. Oral Surg Oral Med Oral Pathol 1977;43:391-401.

6. Furst L, Pharoah M, Phillips J. Recurrence of an ameloblastic fibro-odontoma in a 9-year-old boy. J Oral Maxillofac Surg 1999;57:620-3.

7. Buchner A, Kaffe I, Vered M. Clinical and radiological profile of ameloblasticfibro-odontoma: an update on an uncommon odontogenic tumor based on a critical analysis of 114 cases. Head Neck Pathol 2013;7:54-63.

8. Straith FE. Odontoma. A rare type. Report of a case. Dent Dig 1936;42:196.

9. Slootweg PJ. An analysis of the interrelationship of the mixed odontogenictumors-ameloblastic fibroma, ameloblastic fibro-odontoma, and the odontoma. Oral Surg Oral Med Oral Pathol 1981;51:266-76.

10. Gunhan O, Erseven G, Ruacan S, Celasun B, Aydintug Y, Ergun E, Demiriz M. Odontogenic tumors. A series of 409 cases. Aust Dent J 1990;35:518-22.

11. Buchner A, Vered M. Ameloblastic fibroma: a stage in the development of a hamartomatousodontoma or a true neoplasm? Critical analysis of 162 previously reported cases plus 10 new cases. Oral Surg Oral Med Oral Pathol Oral Radiol 2013;116:598-606.

12. Muller S, Vered M. Ameloblastic fibroma. In: El-Naggar AK, Chan JKC, Grandis JR, Takata T, Slootweg PJ, editors. WHO Classification of Head and Neck Tumours, 4th ed. Lyon: IARC; 2017. p. 222-3.

13. Speight PM, Takata T. New tumour entities in the 4th edition of the World Health Organization Classification of Head and Neck tumours: odontogenic and maxillofacial bone tumours. Virchows Arch 2018;472:331-9.

14. Okura M, Nakahara H, Matsuya T. Treatment of ameloblastic fibro-odontoma without removal of the associated impacted permanent tooth: report of cases. J Oral Maxillofac Surg 1992;50:1094-7.

15. Friedrich RE, Siegert J, Donath K, Jäkel KT. Recurrent ameloblastic fibro-odontomain a 10-year-old boy. J Oral Maxillofac Surg 2001;59:1362-6. 